\title{
Correlations between Width of Keratinized Gingiva and Supracrestal Gingival Tissues Dimensions: A Retrospective Clinical Study
}

\author{
Fatme Mouchref Hamasni ${ }^{1}$, Fady El Hajj ${ }^{2}$
}

\begin{abstract}
Aim: The aim of this retrospective study is to assess potential correlation between the width of the keratinized gingiva (KG), and the dimensions of the supracrestal gingival tissue (SGT) components.

Materials and methods: On the sample of 259 teeth of 79 patients, the following measurements were collected: width of KG, sulcus depth (SD), SGT, and biological width (BW) dimensions; separate correlations between measured elements were computed for males and females, for anterior and posterior, and for maxillary and mandibular teeth separately.

Results: Correlations between buccal KG and BW were present only for the upper anterior teeth and were nonsignificant in the female subsample, whereas the correlation between lingual KG and SGT were present only in females. Additionally, correlations between buccal KG and SD were present in upper anterior teeth only and were absent in the male subgroup.

Conclusion: The width of the KG cannot routinely be used as an indicator for the dimensions of the SGT components.

Clinical significance: While the width of the KG can hardly be a useful indicator in upper anterior teeth, probing depth and bone sounding prior to prosthetic rehabilitation remains an essential tool to ensure tissue preservation.
\end{abstract}

Keywords: Correlation, keratinized gingiva, supracrestal gingival tissue.

The Journal of Contemporary Dental Practice (2021): 10.5005/jp-journals-10024-3022

\section{INTRODUCTION}

Understanding the relationship between restorative margins and periodontal tissue health is principal toward ensuring a healthy periodontium, proper patient comfort and dental function, and satisfaction with esthetic outcomes. To achieve these goals and maintain the stability of the periodontal tissues around prosthetic elements, the majority of researchers strongly advise an appropriate examination of the periodontium (tissue biotype, keratinized gingiva (KG), biological width (BW), sulcus depth (SD), and supracrestal gingival tissue (SGT)) to guide the restorative and prosthetic procedures and to use the suggested less traumatic one.

The static concept of the BW, which was considered as the sacred area in 1994, has been tentatively replaced in periodontalrestorative therapy by a model represented by the apicocoronal dimension of the SGT, including the BW and SD. The dimension and relationship of this dentogingival junction have been the subject of interest of several histological publications performed on both human cadavers ${ }^{1,2}$ and human healthy teeth; ${ }^{3}$ authors noticed that the BW and the SGT were found to be patient and tooth specific, ranging from $0.75 \mathrm{~mm}$ in some patients to $4.33 \mathrm{~mm}$ in others, and the epithelial attachment was significantly greater on tooth surfaces adjacent to subgingival restorations.

Several clinical studies ${ }^{4-9}$ were published concerning the dimension of the SGT. All results reported confirming the presence of a wide range of intra- and inter-individual variability.

Similar to the SGT, the KG dimension in height and width has been studied considering its importance in providing a firm and stable base for maintaining good oral hygiene and preserving healthy periodontium during restorative and prosthetic therapy.

\footnotetext{
1,2Department of Periodontology. Lebanese University School of Dentistry, Hadat, Lebanon
}

Corresponding Author: Fatme Mouchref Hamasni, Department of Periodontology. Lebanese University School of Dentistry, Hadat, Lebanon, e-mail: fatmehamsni@gmail.com

How to cite this article: Hamasni FM, El Hajj F. Correlations between Width of Keratinized Gingiva and Supracrestal Gingival Tissues Dimensions: A Retrospective Clinical Study. J Contemp Dent Pract 2021;22(1):18-22.

Source of support: Nil

Conflict of interest: None

Lang et al. ${ }^{10}$ examined the width of the facial and lingual KG to determine the minimum amount required for the adequate maintenance of gingival health, authors noted that the facial KG was widest in the region of the upper and lower incisors and narrowest around the maxillary and mandibular canines and first premolars, while the lingual KG exhibited its greatest width in the area of the mandibular premolars and molars and the narrowest in the region of the mandibular incisors. Contrarily, the authors mentioned that all surfaces with less than $2.0 \mathrm{~mm}$ of KG exhibited clinical inflammation and a varying amount of gingival exudate.

The study of the relationship between the width of KG and gingival health has been conducted on both natural and restored teeth. Studies revealed the importance of a wide zone of KG in maintaining tissue health around teeth having submarginal restorations. ${ }^{11}$ Similar results have been reported for the KG surrounding implants whereby significantly greater incidences of 
tissue redness, bleeding on probing, and tissue inflammation were demonstrated surrounding implants with less than $2 \mathrm{~mm}$ of KG. ${ }^{12,13}$ The results of numerous additional studies ${ }^{14}$ have corroborated the presence of a positive correlation between the absence of KG and compromised peri-implant status as assessed by plaque index, bleeding index, and bleeding on probing.

A recent study published by Carvalho et al. ${ }^{15}$ described the correlation between biologic width invasion and the periodontium status; results showed in the test group (restored teeth with BW invasion), a statistically significant relationship between the bleeding on probing and gingival recession and between keratinized gingival height and bone level.

The importance of the $K G$ in maintaining periodontal tissue health and esthetic outcomes around restorative and prosthetic restorations has prompted researchers to study a potential correlation between gingival thickness (GT) and gingival width (GW), probing depth (PD), and papillary fill (PF), results demonstrated a positive correlation between GT and GW and no significant correlation could be found between GT and PD and GT and PF. ${ }^{16}$ Although periodontal tissue dimension and a tentative presence of potential correlation between different components were subjects of numerous studies, there has been no research effort to explore the relationship between the two major components of the periodontium; the width of KG and the dimensions of the SGT. The aim of this retrospective study was to assess the correlation between the width of the KG and the dimension of the SGT and its components with the ultimate aim of developing a clinical tool for improved restorative outcomes.

\section{Materials and Methods}

\section{Sample}

Backup folders of all patients attending the periodontology department at the Lebanese University, Faculty of Dentistry, Hadat Lebanon, between 2010 and 2016 for prosthetic crown lengthening surgery were reviewed. All folders that fulfilled the inclusions and exclusions criteria of the study were selected. A total of 79 systemically healthy adult patients ( 61 women and 18 men ranging between 20 and 60 years of age) were the sample found to be satisfying the prerequisite conditions for the study, represented by 56 teeth in males and 203 teeth in females with a total number of 1,036 sites in 259 teeth (93 teeth in the anterior maxilla, 11 teeth in the anterior mandible, 81 teeth in the posterior maxilla, and 74 teeth in the posterior mandible).

Inclusion criteria: All folders completed by a postgraduate resident of the department of periodontology, and filled prior to surgery with the following required measurements: width of the KG, SD, BW, and SGT dimensions, and corrected and signed by a faculty member. Exclusion criteria: All folders presented one of the following conditions: (1) gingival inflammation (full-mouth bleeding scores and full-mouth plaque scores $<20 \%){ }_{1}^{17}(2)$ history of periodontal or orthodontic treatment, (3) gingival recession, (4) presence of altered passive eruption, (5) tooth mobility or furcation involvement, (6) intake of medications known to be associated with gingival overgrowth (calcium channel blockers, cyclosporin, and diphenylhydantoin), (7) heavy smokers (more than 10 cigarettes per day). and (8) the presence of diseases or conditions that may affect periodontal tissue status. Approval for conducting the study was granted by the scientific committee of the faculty.

\section{Measurements}

The following measurements were collected prior to the surgery: (1) SD, represented by the distance from the gingival margin to the bottom of the sulcus, measured at the six tooth sites (mesiobuccal, midbuccal, distobuccal, distolingual or distopalatal, midlingual or midpalatal, and mesiolingual or mesiopalatal); (2) SGT dimension, represented by the distance from the gingival margin to the bone crest, assessed at the same six sites; (3) BW, calculated by subtracting the SD from the SGT values at the six sites; and (4) width of the KG, measured from the free gingival margin to the mucogingival line at the midbuccal and midlingual aspects of the tooth.

According to the department policy, all periodontal data were collected using a periodontal probe (XP23UNC15, Hu Friedy, Chicago, Illinois, USA) and rounded to the nearest millimeter, and in case the numbers were not concordant between the resident and the faculty member, the mean value was taken.

\section{Statistical Analysis}

Data distributions of buccal and lingual KG failed the normality Shapiro-Wilk tests. Therefore, the Spearman correlation coefficients $\left(r_{s}\right)$ were employed to gauge the linear correlation between these variables and the SGT, BW, and SD in the total sample. Separate correlations were also computed for males and females, for anterior and posterior teeth, and for maxillary and mandibular teeth separately.

An alpha level of 0.05 was used as the decision point for statistical significance. All statistical analyses were conducted using the Statistical Package for Social Sciences (IBM SPSS ${ }^{\circledR}$, version 23.0, Armonk, NY).

\section{Results}

\section{Correlations with Buccal Keratinized Gingiva}

The correlations between buccal SGT and width of buccal KG were all weak and statistically nonsignificant for all assessed teeth (upper, lower, anterior, and posterior) in both males and females and in the overall sample (Table $1 ; p>0.05$ ). Correlation coefficients ranged from $r_{\mathrm{s}}=0.013$ for upper posterior teeth in males $(p=0.964)$ to 0.365 for lower anterior teeth in females $(p=0.477)$.

The correlations between buccal BW and width of buccal KG were weak and statistically nonsignificant when assessing all teeth combined in males and females as well as in the overall sample (Table 2; $p$ >0.05). However, when assessing the upper anterior teeth, the correlation was statistically significant in the overall sample $\left(r_{\mathrm{s}}=0.261 ; p=0.012\right)$ and in the male subsample $\left(r_{s}=0.653 ; p=0.003\right)$ but not in females $\left(r_{s}=0.179 ; p=0.125\right)$. For the lower anterior teeth, on the contrary, correlations between buccal BW and buccal KG were all nonsignificant $(p>0.05)$. All posterior teeth, upper and lower, also showed no significant correlations with the exception of the mandibular teeth in females $\left(r_{\mathrm{s}}=0.278 ; p=0.038\right)$.

A similar trend was observed for the correlation between the width of buccal KG and the SD. All correlations were not statistically significant (Table 3; $p>0.05$ ) except when assessing the upper anterior teeth in the total sample $\left(r_{\mathrm{s}}=-0.346 ; p=0.001\right)$ and in the female group $\left(r_{s}=-0.34 ; p=0.003\right)$ where a significant negative correlation existed. 
Table 1: Correlations between supracrestal gingival tissue (SGT) and width of keratinized gingiva on the buccal (BKG) and lingual (LKG) sides

\begin{tabular}{|c|c|c|c|c|c|c|c|c|c|}
\hline & \multicolumn{9}{|c|}{$S G T$} \\
\hline & \multicolumn{3}{|c|}{ Overall } & \multicolumn{3}{|c|}{ Males } & \multicolumn{3}{|c|}{ Females } \\
\hline & $n$ & $r_{s}$ & $p$ & $n$ & $r_{s}$ & $p$ & $n$ & $r_{s}$ & $p$ \\
\hline \multicolumn{10}{|l|}{ BKG } \\
\hline All teeth & 259 & 0.081 & 0.196 & 56 & 0.174 & 0.201 & 203 & 0.049 & 0.492 \\
\hline \multicolumn{10}{|c|}{ Upper teeth } \\
\hline Anterior & 93 & 0.049 & 0.642 & 18 & 0.362 & 0.139 & 75 & -0.029 & 0.804 \\
\hline Posterior & 81 & 0.131 & 0.242 & 15 & 0.013 & 0.964 & 66 & 0.131 & 0.294 \\
\hline \multicolumn{10}{|c|}{ Lower teeth } \\
\hline Anterior & 11 & 0.145 & 0.671 & 5 & -0.057 & 0.927 & 6 & 0.365 & 0.477 \\
\hline Posterior & 74 & 0.193 & 0.099 & 18 & 0.363 & 0.138 & 56 & 0.151 & 0.265 \\
\hline \multicolumn{10}{|l|}{ LKG } \\
\hline $\begin{array}{l}\text { All lower } \\
\text { teeth }\end{array}$ & 73 & 0.1 & 0.401 & 19 & 0.003 & 0.99 & 54 & 0.116 & 0.402 \\
\hline Anterior & 9 & $0.684^{*}$ & 0.042 & 3 & 0.866 & 0.333 & 6 & $0.867^{*}$ & 0.025 \\
\hline Posterior & 64 & -0.037 & 0.774 & 16 & -0.218 & 0.417 & 48 & -0.002 & 0.987 \\
\hline
\end{tabular}

"Statistically significant at $p<0.05 ;{ }^{* * *}$ Statistically significant at $p<0.01$; Correlation coefficients are Spearman's rank correlation coefficient $\left(r_{s}\right)$

Table 2: Correlations between buccal biological width (BW) and width of keratinized gingiva on the buccal (BKG) and lingual (LKG) sides

\begin{tabular}{|c|c|c|c|c|c|c|c|c|c|}
\hline & \multicolumn{9}{|c|}{$B W$} \\
\hline & \multicolumn{3}{|c|}{ Overall } & \multicolumn{3}{|c|}{ Males } & \multicolumn{3}{|c|}{ Females } \\
\hline & $n$ & $r_{s}$ & $p$ & $n$ & $r_{s}$ & $p$ & $n$ & $r_{s}$ & $p$ \\
\hline \multicolumn{10}{|l|}{ BKG } \\
\hline All teeth & 259 & 0.051 & 0.418 & 56 & 0.087 & 0.523 & 203 & 0.014 & 0.847 \\
\hline \multicolumn{10}{|c|}{ Upper teeth } \\
\hline Anterior & 93 & $0.261^{* *}$ & 0.012 & 18 & $0.653^{* *}$ & 0.003 & 75 & 0.179 & 0.125 \\
\hline Posterior & 81 & -0.120 & 0.287 & 15 & -0.374 & 0.170 & 66 & -0.115 & 0.358 \\
\hline \multicolumn{10}{|c|}{ Lower teeth } \\
\hline Anterior & 11 & -0.439 & 0.177 & 5 & -0.229 & 0.710 & 6 & -0.612 & 0.196 \\
\hline Posterior & 74 & 0.222 & 0.057 & 18 & 0.136 & 0.590 & 56 & $0.278^{*}$ & 0.038 \\
\hline \multicolumn{10}{|l|}{ LKG } \\
\hline $\begin{array}{l}\text { All lower } \\
\text { teeth }\end{array}$ & 73 & -0.144 & 0.225 & 19 & -0.188 & 0.442 & 54 & -0.095 & 0.493 \\
\hline Anterior & 9 & 0.246 & 0.523 & 3 & 0.000 & 1.000 & 6 & -0.112 & 0.833 \\
\hline Posterior & 64 & -0.210 & 0.095 & 16 & -0.16 & 0.555 & 48 & -0.197 & 0.179 \\
\hline
\end{tabular}

*Statistically significant at $p<0.05$; **Statistically significant at $p<0.01$; Correlation coefficients are Spearman's rank correlation coefficient $\left(r_{\mathrm{s}}\right)$

\section{Correlations with Lingual Keratinized Gingiva}

The correlations between lingual SGT and width of lingual KG in the lower teeth were statistically significant only when assessing the anterior ones (Table 1; $p<0.05$ ). Coefficients were large and significant in the overall sample $\left(r_{\mathrm{s}}=0.684 ; p=0.042\right)$ and in the female subsample $\left(r_{\mathrm{s}}=0.876 ; p=0.025\right)$ but the relationship was not significant in males despite the large correlation coefficient $\left(r_{\mathrm{s}}=0.886 ; p=0.333\right)$.

The correlations between the width of lingual KG and both lingual BW and SD were all weak and statistically nonsignificant when assessing all lower teeth in males and females as well as in the overall sample (Tables 2 and $3 ; p>0.05$ ).

\section{Discussion}

This study explored the correlations between the width of KG and the dimensions of SD, BW, and SGT in an effort to produce an easy clinical tool for prosthetic and restorative rehabilitation, and to simplify the collaboration between periodontics and restorative dentistry disciplines. ${ }^{18,19}$ The presence of an adequate band of KG required for maintaining tissue health around teeth and implants has been a subject of interest for many authors. ${ }^{11,13,18,20}$ All results reported that the presence of a band $\geq 2 \mathrm{~mm}$ of attached keratinized mucosa influences the long-term soft tissue stability, Different histological studies were performed to assess the dimension of the different periodontal components; the BW, SD, and SGT. Gargiulo 
Table 3: Correlations between buccal sulcus depth (SD) and width of keratinized gingiva on the buccal (BKG) and lingual (LKG) sides

\begin{tabular}{|c|c|c|c|c|c|c|c|c|c|}
\hline & \multicolumn{9}{|c|}{$S D$} \\
\hline & \multicolumn{3}{|c|}{ Overall } & \multicolumn{3}{|c|}{ Males } & \multicolumn{3}{|c|}{ Females } \\
\hline & $n$ & $r_{s}$ & $p$ & $n$ & $r_{s}$ & $p$ & $n$ & $r_{s}$ & $p$ \\
\hline \multicolumn{10}{|l|}{ BKG } \\
\hline All teeth & 259 & -0.009 & 0.884 & 56 & 0.073 & 0.592 & 203 & -0.007 & 0.916 \\
\hline \multicolumn{10}{|c|}{ Upper teeth } \\
\hline Anterior & 93 & $-0.346^{* *}$ & 0.001 & 18 & -0.334 & 0.176 & 75 & $-0.34^{* *}$ & 0.003 \\
\hline Posterior & 81 & 0.139 & 0.216 & 15 & 0.208 & 0.456 & 66 & 0.132 & 0.292 \\
\hline \multicolumn{10}{|c|}{ Lower teeth } \\
\hline Anterior & 11 & 0.297 & 0.375 & 5 & 0 & 1.000 & 6 & 0.456 & 0.363 \\
\hline Posterior & 74 & 0.054 & 0.647 & 18 & 0.262 & 0.293 & 56 & -0.006 & 0.967 \\
\hline \multicolumn{10}{|l|}{ LKG } \\
\hline $\begin{array}{l}\text { All lower } \\
\text { teeth }\end{array}$ & 73 & 0.211 & 0.074 & 19 & 0.307 & 0.2 & 54 & 0.151 & 0.276 \\
\hline Anterior & 9 & 0.496 & 0.174 & 3 & 0.866 & 0.333 & 6 & 0.652 & 0.161 \\
\hline Posterior & 64 & 0.154 & 0.224 & 16 & 0.092 & 0.736 & 48 & 0.134 & 0.365 \\
\hline
\end{tabular}

*Statistically significant at $p<0.05$; **Statistically significant at $p<0.01$; Correlation coefficients are Spearman's rank correlation coefficient $\left(r_{s}\right)$

et al. ${ }^{1}$ described the dimensions of this area on 287 individual teeth from 30 decalcified human autopsy specimens and reported a mean dimension of $0.69,0.97$, and $1.07 \mathrm{~mm}$ for the SD, epithelial attachment, and connective tissue attachment respectively with the BW stated to be $2.04 \mathrm{~mm}$. Whereas Vacek et al. ${ }^{2}$ when conducted a similar study on 171 tooth surfaces from a non-decalcified human cadaver specimen, reported a mean measurement of $1.34 \mathrm{~mm}$ for SD, $1.14 \mathrm{~mm}$ for epithelial attachment, and $0.77 \mathrm{~mm}$ for connective tissue attachment. This is a more recent and the first human histometric study on 24 healthy teeth with demineralized block sections.

Tristão et al. ${ }^{3}$ noted mean measurements of $1.58 \pm 0.41 \mathrm{~mm}$ for the SD, $1.18 \pm 0.42 \mathrm{~mm}$ for the epithelial with the connective tissue attachment, and $2.75 \pm 0.59 \mathrm{~mm}$ for the SGT. Several clinical studies aiming to assess the dimensions of these components were performed in male and female and for anterior and posterior teeth ${ }^{7}$, and before and after crown lengthening procedure; $5,6,8,9$ no studies on a potential presence of such correlation between the width of KG and these components were previously performed.

Many authors emphasized the respect of the BW integrity and the preservation of the genetically coded SGT dimensions as keys to success in restorative and prosthetic rehabilitation. ${ }^{21}$ In regards to the BW, the variability of its dimensions assessed by Hamasni et al. ${ }^{22}$ on 504 tooth sites supported the results of two systematic reviews previously published by Kosyfaki et al. ${ }^{23}$ and Schmidt et al. ${ }^{24}$ and the results of a clinical study performed by Al-Rasheed et al., ${ }^{25}$ and were close to the histological results published by Tristão et al. ${ }^{3}$ Authors confirmed that the dimensions of the biological complex, junctional epithelium, and connective tissue attachment are of clinical relevance, and the use of $2.04 \mathrm{~mm}$ as a standard representative of the mean value could mask the actual clinical situation. Similar to the BW, the variability of SGT dimensions and their relation to the tissue biotype was evaluated. Arora et al., ${ }^{8}$ in a cross-sectional study of 1,932 sites in 366 teeth, mentioned that the thick-flat gingival biotype is characterized by a large band of KG, exhibiting greater median SGT than the thin-scalloped biotype. These results are in concordance with our finding in the anterior lower teeth when the correlations between lingual SGT and the width of lingual KG were statistically significant but was absent in the overall sample when assessing the buccal KG and the buccal SGT. Whereas a statistically significant positive correlation was noticed between the buccal KG and the buccal BW in the upper anterior teeth of the overall sample and in the male subsample. The results published by Goaslind, ${ }^{26}$ Olsson et al., ${ }^{27}$ and Müller et al. ${ }^{28}$ concerning the relation between GT and SD showed a positive relationship between the thickness of free gingiva and the SD. Contrarily to the recent results published by Singh et al. ${ }^{16}$ where authors confirmed the presence of a positive correlation between GT and GW, and a weak negative correlation between GT and SD, our results demonstrated the absence of positive relationships between the width of buccal KG and the SD except when assessing the upper anterior teeth in the total sample and in the female group. The inconstant correlations between the width of KG and the SGT, BW, and SD dimensions in different gender and different teeth sites were found in this study. The variability in results published by several authors concerning periodontal tissue dimensions and the relationships between different constituents reflected the underlying large variability of these supraosseous components and are likely reflective of differences in unique patient characteristics, tooth type, and tooth side. The lake of studies interested in finding a potential correlation between the major components of the periodontium; the KG and the SGT, and within the limitation of this study, the width of KG commonly associated with a thick periodontium cannot be a clinical indicator of the dimension of the SGT, neither the BW nor the SD.

\section{Conclusion}

While the width of the KG may be a useful indicator of the BW dimension in the upper anterior teeth at the buccal side, sulcular probing and bone sounding prior to prosthetic or restorative rehabilitation remains an essential clinical tool for the practitioner to avoid periodontal tissues traumatisms and to ensure the preservation of tissue integrity and esthetic outcomes. 


\section{References}

1. Gargiulo A, Wentz F, Orban B. Dimensions and relations of the dentogingival junction in humans. J Periodontol 1961;32(3):261-267. DOI: 10.1902/jop.1961.32.3.261.

2. Vacek JS, Gher ME, Assad DA, et al. The dimensions of the human dentogingival junction. Int J Periodontics Restorative Dent 1994;14(2):154-165. DOI: 10.11607/prd.

3. Tristão G, Barboza CA, Rodrigues DM, et al. Supracrestal gingival tissue measurement in normal periodontium: a human histometric study. Int J Periodontics Restorative Dent 2014;34(1):97-102. DOI: 10.11607/ prd.1353.

4. Smukler $\mathrm{H}, \mathrm{Chaibi} \mathrm{M}$. Periodontal and dental considerations in clinical crown extension: a rational basis for treatment. Int J Periodontics Restorative Dent 1997;17:464-477. PMID: 9497735.

5. Lanning SK, Waldrop TC, Gunsolley JC, et al. Surgical crown lengthening: evaluation of the biologic width. J Periodontol 2003;74(4):468-474. DOI: 10.1902/jop.2003.74.4.468.

6. Perez JR, Smukler H, Nunn ME. Clinical evaluation of the supraosseous gingivae before and after crown lengthening. J Periodontol 2007;78(6):1023-1030. DOI: 10.1902/jop.2007.060485.

7. Barboza EP, MonteAlto RF, Ferreira VF, et al. Supracrestal gingival tissue measurements in healthy human periodontium. Int J Periodontics Restorative Dent 2008;28(1):55-61. PMID: 18351203.

8. Arora R, Narula SC, Sharma RK, et al. Supracrestal gingival tissue: assessing relation with periodontal biotypes in a healthy periodontium. Int J Periodontics Restorative Dent 2013;33(6):763-771. DOI: 10.11607/prd.1501.

9. Zweers J, Thomas RZ, Slot DE, et al. Characteristics of periodontal biotype, its dimensions, associations and prevalence-a systematic review. J Clin Periodontol 2014;41(10):958-971. DOI: 10.1111/ jcpe. 12275 .

10. Lang NP, Löe H. The relationship between the width of keratinized gingiva and gingival health. J Periodontol 1972;43(10):623-627. DOI: 10.1902/jop.1972.43.10.623.

11. Stetler K, Bissada N. Significance of the width of keratinized gingiva on the periodontal status of teeth with submarginal restorations. J Periodontol 1987;58(10):696-700. DOI: 10.1902/jop.1987.58. 10.696.

12. Bouri A, Bissada N, Al-Zahrani MS, et al. Width of keratinized gingiva and the health status of the supporting tissues around dental implants. Int J Oral Maxillofac Implants 2008;23(2):323-326. PMID:18548930.
13. Famili $P$, Desai $A$. The importance of keratinized gingiva surrounding dental implants. J Dent Health Oral Disord Ther 2015;2(5):153-155. DOI: $10.15406 /$ jdhodt.2015.02.00061.

14. Dhir S. The peri-implant esthetics: an unforgettable entity. J Indian Soc Periodontol 2011;15(2):98-102. DOI: 10.4103/0972-124x.84375.

15. Carvalho B, Duarte $C$, Silva JF, et al. Clinical and radiographic evaluation of the Periodontium with biologic width invasion. BMC Oral Health 2020;20(1):116. DOI: 10.1186/s12903-020-01101-x.

16. Singh J, Rathod VJ, Rao PR, et al. Correlation of gingival thickness with gingival width, probing depth, and papillary fill in maxillary anterior teeth in students of a dental college in Navi Mumbai. Contemp Clin Dent 2016;7(4):535-538. DOI: 10.4103/0976-237X.194117.

17. O'Leary TJ, Drake RB, Naylor JE. The plaque control record. J Periodontol 1972;43(1):38. DOI: 10.1902/jop.1972.43.1.38.

18. Hsu YT, Huang NC, Wang HL. Relationship between periodontics and prosthodontics: the two-way street. J Prosthodont Implantol 2015;4(1):4-11. DOI: 10.6926/JPI.201505_4(1).0001.

19. Pulcini MG, Vitelli C, Dian A, et al. Single tooth prosthetic restoration through surgical crown lengthening, conservative therapies and CAD-CAM milled restoration in lithium-disilicate: a case report. Acta Stomatol Croat 2019;53(3):371-378. DOI: 10.15644/asc53/4/8.

20. Del Amo FSL, Yu S, Sammartino G, et al. Peri-implant soft tissue management: cairo opinion. consensus conference. Int J Environ Res Public Health 2020;17(7):2281. DOI: 10.3390/ijerph17072281.

21. Marzadori $M$, Stefanini $M$, Sangiorgi $M$, et al. Crown lengthening and restorative procedures in the esthetic zone. Periodontol 2000 2018;77(1):84-92. DOI: 10.1111/prd.12208.

22. Hamasni FM, El Hajj F. Comparison of the clinical biological width with the published standard histologic mean values. J Int Soc Prev Community Dent 2017;7(5):264-271. DOI: 10.4103/jispcd. JISPCD_261_17.

23. Kosyfaki P, Martín MP, Strub JR. Relationship between crowns and the periodontium: a literature update. Quintessence Int 2010;41(2):109_ 122. PMID: 20165743.

24. Schmidt JC, Sahrmann P, Weiger R, et al. Biologic width dimensions-a systematic review. J Clin Periodontol 2013;40(5):493-504. DOI: 10.1111/ jcpe.12078.

25. Al-Rasheed A, Ghabban W, Zakour A. Clinical biological width dimension around dentition of a selected Saudi population. Pak Oral Dent J 2005;25(1):81-86. P-ISSN: 1012-8700, E-ISSN: 1996-4439.

26. Goaslind GD, Robertson PB, Mahan CJ, et al. Thickness of facial gingiva. J Periodontol 1977;48(12):768-771. DOI: 10.1902/jop.1977.48.12.768.

27. Olsson M, Lindhe J, Marinello CP. On the relationship between crown form and clinical features of the gingiva in adolescents.J Clin Periodontol 1993;20(8):570-577. DOI: 10.1111/j.1600-051x.1993.tb00773.x.

28. Müller HP, Schaller N, Eger T, et al. Thickness of masticatory mucosa. J Clin Periodontol 2001;27(6):431-436. DOI: 10.1034/j.1600051x.2000.027006431.x. 